Published in final edited form as:

Clin Lung Cancer. 2018 May ; 19(3): 260-269.e3. doi:10.1016/j.cllc.2017.12.003.

\title{
Impact of Prophylactic Cranial Irradiation on Overall Survival in Metastatic Small Cell Lung Cancer: A Propensity Score Matched Analysis
}

\author{
Sonam Sharma ${ }^{1}$, Matthew T McMillan ${ }^{1}$, Abigail Doucette ${ }^{1}$, Roger B. Cohen ${ }^{2}$, Abigail \\ Berman ${ }^{1}$, William Levin ${ }^{1}$, Charles B Simone ${ }^{3}{ }^{3}$, and Jacob Shabason ${ }^{1}$ \\ ${ }^{1}$ Department of Radiation Oncology, Perelman School of Medicine at the University of \\ Pennsylvania \\ ${ }^{2}$ Department of Medical Oncology, Perelman School of Medicine at the University of Pennsylvania \\ ${ }^{3}$ Department of Radiation Oncology, University of Maryland School of Medicine
}

\begin{abstract}
Introduction-Patients with small cell lung cancer (SCLC) have a high incidence of occult brain metastases and are often treated with prophylactic cranial irradiation (PCI). Despite a small survival advantage in some studies, the role of PCI in extensive stage SCLC remains controversial. We utilized the National Cancer Data Base to assess survival of patients with metastatic SCLC treated with PCI.
\end{abstract}

Methods-Metastatic SCLC patients without brain metastases were identified. To minimize treatment selection bias, patients with an overall survival (OS) $<6$ months were excluded. Cox regression identified variables associated with OS. Patients were propensity score-matched on factors associated with receipt of PCI or OS. The impact of PCI on OS was examined using Kaplan Meier estimates.

Results-In the overall cohort $(\mathrm{N}=4,257)$, treatment with PCI $(\mathrm{n}=473)$ was associated with improved survival (HR 0.66, 95\% CI 0.60-0.74, p<0.0001). Comparisons of propensity score

Corresponding Author: Jacob Shabason, Department of Radiation Oncology, PCAM-2 West, 3400 Civic Center Blvd, Philadelphia, PA 19104, Phone: 215-662-2428, Fax: 215-349-8975, jacob.shabason@uphs.upenn.edu.

Conflict of Interest or Financial Disclosures: None

Author Contributions:

Conception and design: Sharma, Shabason

Collection and assembly of data: Sharma, McMillan, Shabason

Manuscript Writing: All authors

Data analysis and interpretation: All authors

Final approval of manuscript: All authors

Disclaimer: The data used in this study are derived from a de-identified National Cancer Data Base file. The American College of Surgeons and the Commission on Cancer have not verified and are not responsible for the analytical and statistical methodology used or the conclusions drawn from these data by the investigators. The interpretation and reporting of these data are the sole responsibility of the authors

Publisher's Disclaimer: This is a PDF file of an unedited manuscript that has been accepted for publication. As a service to our customers we are providing this early version of the manuscript. The manuscript will undergo copyediting, typesetting, and review of the resulting proof before it is published in its final citable form. Please note that during the production process errors may be discovered which could affect the content, and all legal disclaimers that apply to the journal pertain. 
matched cohorts revealed a significant survival benefit for patients who received PCI in median OS (13.9 vs. 11.1 months, $\mathrm{p}<0.0001)$, as well as 1 - and 2 -year OS (61.2\% vs. $44.0 \%$ and $19.8 \%$ vs. $11.5 \%$, respectively; $\mathrm{p}<0.0001$ ). This survival benefit persisted even after excluding patients who survived $<9$ months (median: 15.3 vs. 12.9 months, $\mathrm{p}<0.0001$ ). On multivariable analysis, predictors of receipt of PCI were Caucasian race, younger age, and lower Charlson/Deyo score.

Conclusion-Utilizing a modern population-based data set, we show that metastatic SCLC patients treated with PCI have significantly improved OS. This large retrospective study helps address the conflicting prospective data.

\section{Keywords}

small cell lung cancer; national cancer database; prophylactic cranial irradiation; overall survival

\section{INTRODUCTION}

Small cell lung cancer (SCLC) comprises approximately $13 \%$ of all new lung cancer diagnoses with approximately 31,000 cases annually in the United States. ${ }^{1,2}$ SCLC is characterized by its aggressive nature, rapid doubling time, and high metastatic potential. The majority of patients (60-70\%) present with disseminated, extensive-stage (ES) disease at diagnosis, for which the primary treatment is chemotherapy. 3,4

SCLC has a notoriously high rate of brain metastases, with over 50\% of patients developing intracranial involvement over the course of their disease. ${ }^{5,6}$ As a result, for patients who respond well to initial chemotherapy, prophylactic cranial irradiation (PCI) is used to decrease the risk of brain metastases and the associated neurological morbidity of intracranial progression as shown in multiple meta-analyses. ${ }^{7,8,9}$ In patients with limitedstage disease, there is evidence that PCI decreases the risk of brain metastases and improves survival. ${ }^{8,9}$ Therefore, the National Comprehensive Cancer Network (NCCN) Guidelines provide a category 1 recommendation to offer PCI in patients with limited-stage SCLC who respond to initial therapy. ${ }^{3}$

In patients with ES disease, PCI also decreases the risk of developing symptomatic brain metastases, ${ }^{10,11}$ but its impact on overall survival is controversial. PCI appeared to offer a survival benefit in one randomized trial of patients with ES disease who responded to chemotherapy. ${ }^{10}$ However, this trial has been criticized, as patients were not screened for brain metastases with brain imaging prior to PCI unless they had neurological symptoms. As a result, some patients likely had brain metastases at the time of PCI and may have achieved a survival benefit through the treatment of known intracranial disease. Per current NCCN guidelines, PCI is generally reserved for patients with an objective clinical or radiographic response to chemotherapy and negative post-chemotherapy brain imaging. ${ }^{3}$ Interestingly, the results of another recent phase III trial found that ES-SCLC patients who responded to initial chemotherapy and had a negative brain MRI did not have a survival benefit when treated with PCI. ${ }^{11}$

Given the disparate results of prospective trials on the role of PCI in ES-SCLC and the low likelihood that additional randomized studies will be performed, we undertook this study to 
better understand the clinical impact of PCI on survival outcomes using a modern, population-based database at the national level. While we recognize that prospective randomized control trials are the gold standard, we hope that this study adds clinically meaningful data to an area of controversy. We assessed clinical outcomes using the National Cancer Data Base (NCDB) and propensity score-matching to better elucidate the potential benefits of PCI in patients with ES-SCLC and to help direct the clinical management of these patients. We hypothesized that PCI would confer an overall survival (OS) benefit in patients with ES-SCLC without brain metastases who respond to standard chemotherapy.

\section{METHODS}

\section{Data Source}

After obtaining approval from our Institutional Review Board, we conducted a propensity score-matched cohort study using the NCDB. The NCDB is a large national oncology registry sponsored by the American College of Surgeons and the American Cancer Society encompassing over 1,500 Commission on Cancer $(\mathrm{CoC})$ institutions. Approximately 70 percent of new nationwide cancer diagnoses are recorded in this database. ${ }^{12}$

\section{Patient Selection}

Patients with metastatic SCLC without brain metastases treated with chemotherapy between 2010 and 2012 were identified in the NCDB. Of note, the study period commenced in 2010 when the NCDB began recording the presence of brain metastases and ended in 2012 to allow for adequate follow-up and survival data to perform risk adjusted survival analysis. Patients were excluded if they had non-metastatic disease, known brain metastases or unknown intracranial disease status, underwent surgery, received doses of whole brain radiation (WBRT) outside the typical prophylactic dose range ( $<20 \mathrm{~Gy}$ or $\geq 30 \mathrm{~Gy}$ ), or did not receive chemotherapy (Figure 1). To account for bias of delivery of PCI, patients with an OS < 6 months were excluded to eliminate those who likely did not respond to or relapsed quickly after first line chemotherapy, and thus would not be optimal candidates for PCI. We also conducted the same analysis including all patients without a minimum survival cutoff.

\section{Definition of PCI}

To exclude patients who received therapeutic WBRT, receipt of PCI was defined as those patients with non-intracranial metastatic SCLC at diagnosis who received WBRT to a dose consistent with standard PCI doses of greater than or equal to $20 \mathrm{~Gy}$ and less than $30 \mathrm{~Gy}$.

\section{Endpoints}

The primary outcome was the impact of PCI on patient OS in metastatic SCLC. Overall survival was defined as the interval between diagnosis and date of death or last follow-up visit. In addition, patient, clinical, and demographic factors associated with receipt of PCI were identified. 


\section{Independent Variables}

Patient characteristics included age at diagnosis, gender, and race. Clinical characteristics incorporated Charlson/Deyo comorbidity score, primary tumor location, tumor grade, and clinical TNM classification. Demographic factors assessed were insurance status, income, and facility type. Facility type was defined as academic or non-academic based on $\mathrm{CoC}$ designation. ${ }^{13}$

\section{Statistical Analysis}

Descriptive statistics are presented as frequencies for categorical variables and median (interquartile range $[\mathrm{IQR}]$ ) for continuous variables. Pearson's $\chi 2$ or Fisher's exact tests were used to analyze categorical variables. Predictors of receipt of PCI were examined using univariable and multivariable logistic regression. Multivariable analysis utilized backward, stepwise logistic regression ( $\mathrm{p} ₫ 0.05$ for entry, $p>0.10$ for removal). OS was analyzed using univariable and multivariable Cox proportional hazards modeling. The multivariable Cox regression used backward stepwise selection ( $\mathrm{p} \unlhd .05$ for entry, $\mathrm{p}>0.10$ for removal).

Using a minimum OS cut-off of 6 months, propensity scores were developed accounting for factors significantly associated with either receipt of PCI or OS in multivariable analysis. These variables included age, gender, race, Charlson Deyo score, insurance type, income, facility type, clinical T classification, clinical $\mathrm{N}$ classification, and clinical $\mathrm{M}$ classification. Patients were then paired 1:1 on these propensity scores using the "greedy" nearest-neighbor matching algorithm without replacement. Standardized differences were estimated before and after matching to evaluate the balance of covariate; values $<0.1$ indicated balance between the treatment groups. Following 1:1 propensity score-matching, OS between matched PCI and no PCI cohorts was examined by Kaplan Meier analysis using KleinMoeschberger methodology. ${ }^{14}$

To further account for potential biases favoring the receipt of PCI in metastatic SCLC patients with more favorable prognoses, a landmark survival analysis was conducted for patients with a minimum OS of 9 months. We additionally conducted the analysis on the entire patient cohort without a minimum survival cutoff. The same propensity scorematching methodology and cohort comparisons described above were used. Statistical analyses were completed using SPSS version 22.0 (IBM Corporation, Armonk, NY). Associations were noted as statistically significant at $\mathrm{p}<0.05$. All tests were two-sided.

\section{RESULTS}

\section{Characteristics of the Overall, Unmatched Study Population}

In the overall cohort of patients with metastatic SCLC without brain metastases who survived at least 6 months (n=4,257), 473 patients $(11.1 \%)$ received PCI, whereas 3,784 patients $(88.9 \%)$ received only chemotherapy without PCI. Amongst the patients who received PCI, the most common dose fractionation was 25 Gy in 10 fractions $(n=391,83 \%)$. Baseline characteristics of the cohorts are shown in Table 1. Prior to propensity score matching, the PCI cohort differed significantly from the no PCI group based on age, race, Charlson/Deyo comorbidity score, and insurance type. There was no difference in gender, 
income level, facility type, primary tumor location, tumor grade, and TNM classification in the unmatched groups (Table 1).

\section{Factors Predicting Receipt of PCI}

On multivariable logistic regression analysis, independent factors that predicted for no PCI included race (black vs. white: OR 0.55, $\mathrm{p}=0.01$ ), age (age $\geq 75$ vs. age <65: OR: 0.65, $\mathrm{p}=0.003$ ), and Charlson/Deyo comorbidity score (score of $\geq 1$ vs. 0 : OR $0.76, p=0.006$ ) (Table 2).

\section{Impact of $\mathrm{PCI}$ on Overall Survival}

On multivariable Cox proportional hazards analysis of the unmatched cohort of patients with a minimum survival of 6 months, treatment with PCI was associated with a significant OS benefit when compared to the no PCI cohort (HR 0.66, 95\% CI 0.60-0.74, p<0.0001). Other factors significantly associated with OS included age, gender, race, Charlson/Deyo comorbidity score, income, $\mathrm{T}$ classification, nodal status, and $\mathrm{M}$ classification (Table 3).

\section{Impact of PCI on Overall Survival in Propensity Score-Matched Cohort}

To account for potential biases favoring the receipt of PCI in patients with more favorable prognoses, we conducted 1:1 propensity score matched survival analyses. In the matched cohort with a minimum survival of 6 months, there were a total of 472 patients in each arm (chemotherapy with or without PCI). Baseline characteristics of the matched patients were well balanced across all variables (Table 1). With a median follow up of 30.4 months, receipt of PCI was associated with a significant benefit in median survival (13.9 months vs. 11.1 months, p <0.0001), 1-year OS (61.2\% vs. $44.0 \%$, p <0.0001) and 2-year OS (19.8\% vs. $11.5 \%, \mathrm{p}<0.0001$ ) (Table 4a, Figure 2a). On subset analysis, receipt of PCI was associated with a significant survival benefit in all patients except for those $\geq 75$ years of age and patients with N0-1 or M1a disease (Supplemental Table 1).

In order to minimize bias, the initial analysis only included patients who survived at least 6 months from diagnosis in an attempt to eliminate those who likely did not respond to or relapsed quickly after first line chemotherapy, and thus would have never been offered PCI. To further minimize bias and to confirm a survival benefit to PCI, a similar analysis was performed for patients with a minimum OS of 9 months. After applying this exclusion criterion, 396 patients (13.8\%) received PCI, whereas 2,465 patients (86.2\%) received only chemotherapy without PCI. These patients had similar baseline characteristics and predictors of receiving PCI to what we previously described (Supplemental Table 2 and 3). After propensity score matching, there were 395 patients in each arm and the groups were well balanced (Supplemental Table 2). Importantly, a propensity score-matched survival analysis again demonstrated a survival benefit for PCI. Specifically, with a median follow up of 29.9 months, PCI led to an improvement in median survival (15.3 months vs. 12.9 months, $p$ $<0.0001)$, 1-year OS (71.4\% vs. $59.5 \%$, p <0.0001) and 2-year OS (23.1\% vs. $15.9 \%$, p $<0.0001$ ) (Table $4 \mathrm{~b}$, Figure $2 \mathrm{~b}$ ). When we conducted the analysis on the entire cohort without a minimum survival cutoff, the median overall survival was 13.6 months in the PCI group versus 8.6 months in the no PCI group ( $\mathrm{p}<0.0001$ ). 


\section{DISCUSSION}

In this study, we analyzed the survival outcomes of patients with metastatic SCLC treated with or without PCI using the NCDB. This represents the largest retrospective study to date assessing the efficacy of PCI in this patient population. We identified 4,257 patients with metastatic SCLC without brain metastases and a minimum survival of at least 6 months treated from 2010 to 2012. After propensity score matching with a median follow-up of 30.4 months, we found that PCI was associated with a significant survival benefit with an improvement in median survival of 13.9 vs. 11.1 months. We saw a similar survival benefit even when excluding patients who survived $<9$ months and when analyzing the entire cohort without a minimum survival cutoff. Additionally, we identified younger age, lower Charlson/Deyo score and Caucasian race as factors associated with receipt of PCI.

Although firmly established in the care of patients with limited-stage SCLC who respond to initial therapy, the use of PCI remains controversial for patients with ES disease. The controversy stems from conflicting reports from prospective clinical trials. The Auperin meta-analysis first suggested a survival benefit for PCI based on an analysis that included patients with both limited- and extensive-stage disease who had a complete response to therapy. ${ }^{8}$ This finding was confirmed with an additional pooled analysis, which also found an overall survival benefit to PCI in both limited and extensive stage disease. ${ }^{15}$ More recently, a phase III trial from the EORTC demonstrated that utilization of PCI in patients with a partial or complete response to chemotherapy resulted in an improvement in OS and a decrease in brain metastases. However, this trial did not routinely screen patients with a brain MRI prior to PCI. ${ }^{10}$ Takahashi and colleagues conducted a similar phase III trial randomizing ES-SCLC patients to PCI versus no PCI, but notably required a screening brain MRI prior to enrollment. Inclusion criteria in this study included ES-SCLC patients with any response to chemotherapy, MRI brain negative for metastases, and an estimated life expectancy $>3$ months. Patients had an MRI brain at 3 month intervals up to 12 months and at 18 and 24 months after enrollment. Results from this trial reported an improvement in control of brain metastases, but there was no survival benefit, and the trial was stopped early at a planned interim analysis demonstrating futility of PCI. ${ }^{11}$ Despite these conflicting data, PCI for patients with ES-SCLC with a good performance status and a response to chemotherapy has a category $2 \mathrm{~A}$ recommendation from the NCCN. ${ }^{3}$ Recent studies surveying United States and Canadian radiation oncologists show that the vast majority (98\%) of those surveyed recommend PCI in patients with ES-SCLC after a good response to initial therapy. ${ }^{16,17}$

Patients and physicians are understandably concerned about the potential toxicities of PCI. Acute toxicities include alopecia, fatigue, headaches, nausea and vomiting. Long-term toxicities range from memory loss to neurocognitive dysfunction. In the EORTC randomized trial, Slotman et al. assessed the impact of PCI on health-related quality of life (HRQOL). Despite a lower risk of symptomatic brain metastases, PCI had a negative effect on a variety of short-term HRQOL outcomes. ${ }^{18}$ However, other trials have not shown a difference in neurocognitive outcomes when comparing PCI to observation. ${ }^{19,20}$ Unfortunately, toxicity data are not collected in the NCDB, but there are a variety of studies looking into reducing 
these toxicities, such as hippocampal sparing intensity-modulated radiation therapy (IMRT)

${ }^{21}$ and memantine. ${ }^{22}$.

The survival outcomes in our study follow similar trends to those in the EORTC trial that showed a benefit for PCI (6.7 vs. 5.4 months, $\mathrm{p}=0.003) .{ }^{10}$ However, the absolute numbers are more comparable to those observed in the recent Japanese trial (11.6 vs. 13.7 months, $\mathrm{p}=0.091) .{ }^{11}$ The overall improvement in survival is likely due to the shared, more recent time period (post-2009) for both our cohort and the Japanese study, whereas the EORTC trial enrolled patients from 2001-2006. The more widespread use of PET staging over the past decade may also have led to stage migration and favorably shifted the overall outcomes. 23

Our study also highlights potentially important healthcare disparities with patients of older age (age $\geq 75$ vs. age <65: OR: 0.65 , $\mathrm{p}=0.003$ ), more comorbidities (Charlson/Deyo score $\geq$ 1 vs. 0 : OR $0.76, p=0.006$ ), and black race (black vs. white: $\mathrm{OR} 0.55, \mathrm{p}=0.01$ ) less likely to receive treatment with PCI. It is understandable why a physician would not recommend PCI due to patient age and performance status for medical concerns. However, the racial disparities we found are more concerning. While we recognize that our findings are subject to biases associated with retrospective and large database studies, these disparities are consistent with published data demonstrating oncologic treatment inequities by race. ${ }^{24,25} \mathrm{In}$ particular, disparities have previously been assessed in patients with lung cancer where studies have indicated that black men have both a higher incidence of lung cancer in the United States as well as higher cancer-related mortality when compared to white men. ${ }^{1,24}$ These findings suggest that racial inequities in treatment recommendations, including the receipt of PCI that was found in our study, may contribute to worse clinical outcomes for black patients, and providing equal access to healthcare may help eliminate these disparities. 26

Furthermore, this study highlights the general lack of use of PCI in US cancer centers, where only $11 \%$ of our population were treated with PCI. This low statistic is surprising given that the vast majority of US and Canadian radiation oncologists would recommend PCI for patients with ES-SCLC after a response to chemotherapy. ${ }^{16,17}$ However, this was prior to the publication of the prospective trial by Takahashi et al. ${ }^{11}$

This study has several important limitations. As with any retrospective analysis, certain unknown biases may exist that cannot be controlled for and could influence the results. Most notably, the data in the NCDB do not indicate why certain patients did not receive PCI. It is possible that some patients progressed through initial chemotherapy, relapsed quickly after systemic treatment, or had a poor performance status precluding treatment with PCI. To minimize these biases, we performed a propensity score-matched analysis before comparing survival outcomes. Moreover, to account for additional biases in the receipt of PCI, we excluded patients with an overall survival $<6$ months to eliminate those who likely did not respond to or relapsed quickly after first line chemotherapy, and thus would have never been offered PCI. We extended our propensity score-matched analysis to those with a minimum survival of 9 months to further minimize these biases and continued to observe similar trends in OS. 
Another, limitation to our study is that the NCDB does not distinguish between the radiation treatment intent, namely PCI versus therapeutic WBRT. To overcome this limitation, we included only patients without brain metastases and categorized PCI as those receiving intracranial radiation doses $<30 \mathrm{~Gy}$ and $\geq 20 \mathrm{~Gy}$. This dose range includes the two recommended doses by the NCCN, including 25 Gy in 10 fractions or 20 Gy in 10 fractions. Furthermore, this dose range fits with recent survey data that suggest that the vast majority of radiation oncologists favor $25 \mathrm{~Gy}$ as the PCI dose ${ }^{17}$. Any patient treated with a radiation dose of $\geq 30$ Gy was omitted from the analysis, as such doses are more typical of therapeutic radiation for known brain metastases. We were also unable to analyze the impact of consolidative thoracic radiation on outcomes since the NCDB lists only one course of radiation per patient, and more specifically the highest radiation dose received. The use of consolidative thoracic radiotherapy was probably low, however, during our study period (2010-2012) as this was prior to the publication of randomized trial data demonstrating the benefit of thoracic RT in ES-SCLC. ${ }^{27}$ Lastly, the fact that only $11.1 \%$ of our population received PCI is surprisingly low and possibly indicative of bias in this study. One hypothesis is that these low numbers may be a result of our decision to omit from the analysis patients receiving $\geq 30 \mathrm{~Gy}$ of radiation. Although this higher dose is usually more indicative of therapeutic WBRT, it is certainly an option for PCI, and, therefore, we may have eliminated some patients who received PCI.

This retrospective cohort study further supports the benefits of PCI in patients with ESSCLC who respond to initial chemotherapy. Based on the results of this large, modern, population-based study, PCI may offer a significant OS benefit in the appropriately selected ES-SCLC patient. Further prospective, randomized trials are needed to reconcile divergent reports of the clinical impact of PCI on survival and further guide the management of these patients.

\section{Supplementary Material}

Refer to Web version on PubMed Central for supplementary material.

\section{Acknowledgments}

Funding: Research reported in this publication was supported by the National Center for Advancing Translational Sciences of the National Institutes of Health under award number KL2TR001879. The content is solely the responsibility of the authors and does not necessarily represent the official views of the National Institutes of Health.

\section{References}

1. Siegel RL, Miller KD, Jemal A. Cancer statistics, 2016. CA Cancer J Clin. 2016; 66(1):7-30. DOI: 10.3322/caac.21332 [PubMed: 26742998]

2. Govindan R, Page N, Morgensztern D, et al. Changing epidemiology of small-cell lung cancer in the United States over the last 30 years: analysis of the surveillance, epidemiologic, and end results database. J Clin Oncol. 2006; 24(28):4539-4544. DOI: 10.1200/JCO.2005.04.4859 [PubMed: 17008692]

3. National Comprehensive Cancer Network (NCCN). Clinical Practice Guidelines in Oncology: Small cell lung cancer (Version I.2017). 
4. Fruh M, De Ruysscher D, Popat S, Crino L, Peters S, Felip E. Small-cell lung cancer (SCLC): ESMO Clinical Practice Guidelines for diagnosis, treatment and follow-up. Ann Oncol. 2013; 24(Suppl 6):vi99-vi105. DOI: 10.1093/annonc/mdt178 [PubMed: 23813929]

5. Nugent JL, Bunn PAJ, Matthews MJ, et al. CNS metastases in small cell bronchogenic carcinoma: increasing frequency and changing pattern with lengthening survival. Cancer. 1979; 44(5):18851893. [PubMed: 227582]

6. Hochstenbag MM, Twijnstra A, Wilmink JT, Wouters EF, ten Velde GP. Asymptomatic brain metastases (BM) in small cell lung cancer (SCLC): MR-imaging is useful at initial diagnosis. J Neurooncol. 2000; 48(3):243-248. [PubMed: 11100822]

7. Le Pechoux C, Sun A, Slotman BJ, De Ruysscher D, Belderbos J, Gore EM. Prophylactic cranial irradiation for patients with lung cancer. Lancet Oncol. 2016; 17(7):e277-e293. DOI: 10.1016/ S1470-2045(16)30065-1 [PubMed: 27396646]

8. Auperin A, Arriagada R, Pignon JP, et al. Prophylactic cranial irradiation for patients with small-cell lung cancer in complete remission. Prophylactic Cranial Irradiation Overview Collaborative Group. N Engl J Med. 1999; 341(7):476-484. DOI: 10.1056/NEJM199908123410703 [PubMed: 10441603]

9. Meert AP, Paesmans M, Berghmans T, et al. Prophylactic cranial irradiation in small cell lung cancer: a systematic review of the literature with meta-analysis. BMC Cancer. 2001; 1:5.doi: 10.1186/1471-2407-1-5 [PubMed: 11432756]

10. Slotman B, Faivre-Finn C, Kramer G, et al. Prophylactic Cranial Irradiation in Small-Cell Lung Cancer. N Engl J Med. 2007; 357(7):664-672. DOI: 10.1634/theoncologist.5-4-293 [PubMed: 17699816]

11. Takahashi T, Yamanaka T, Seto T, et al. Prophylactic cranial irradiation versus observation in patients with extensive-disease small-cell lung cancer: a multicentre, randomised, open-label, phase 3 trial. Lancet Oncol. 2017; 18(5):663-671. DOI: 10.1016/S1470-2045(17)30230-9 [PubMed: 28343976]

12. National Cancer Data Base. American College of Surgeons; https://www.facs.org/qualityprograms/ cancer/ncdb. Published 2015

13. CoC Accreditation Categories. American College of Surgeons; https://www.facs.org/qualityprograms/cancer/accredited/about/categories. Published 2015

14. Austin PC. A critical appraisal of propensity-score matching in the medical literature between 1996 and 2003. Stat Med. 2008; 27(12):2037-2049. DOI: 10.1002/sim.3150 [PubMed: 18038446]

15. Schild SE, Foster NR, Meyers JP, et al. Prophylactic cranial irradiation in small-cell lung cancer: findings from a North Central Cancer Treatment Group Pooled Analysis. Ann Oncol Off J Eur Soc Med Oncol. 2012; 23(11):2919-2924. DOI: 10.1093/annonc/mds123

16. Jain A, Luo J, Chen Y, Henderson MA, Thomas CRJ, Mitin T. Current Patterns of Care for Patients with Extensive-Stage SCLC: Survey of U.S. Radiation Oncologists on Their Recommendations Regarding Prophylactic Cranial Irradiation. J Thorac Oncol. 2016; 11(8):1305-1310. DOI: 10.1016/j.jtho.2016.04.031 [PubMed: 27237826]

17. Shahi J, Wright JR, Gabos Z, Swaminath A. Management of small-cell lung cancer with radiotherapy-a pan-Canadian survey of radiation oncologists. Curr Oncol. 2016; 23(3):184-195. DOI: 10.3747/co.23.3023 [PubMed: 27330347]

18. Slotman BJ, Mauer ME, Bottomley A, et al. Prophylactic Cranial Irradiation in Extensive Disease Small-Cell Lung Cancer: Short-Term Health-Related Quality of Life and Patient Reported Symptoms - Results of an International Phase III Randomized Controlled Trial by the EORTC Radiation Oncology and Lun. J Clin Oncol. 2009; 27(1):78-84. DOI: 10.1200/JCO.2008.17.0746 [PubMed: 19047288]

19. Arriagada R, Le Chevalier T, Borie F, et al. Prophylactic cranial irradiation for patients with smallcell lung cancer in complete remission. J Natl Cancer Inst. 1995; 87(3):183-190. [PubMed: 7707405]

20. Gregor A, Cull A, Stephens RJ, et al. Prophylactic cranial irradiation is indicated following complete response to induction therapy in small cell lung cancer: results of a multicentre randomised trial. United Kingdom Coordinating Committee for Cancer Research (UKCCCR) and the European Organi. Eur J Cancer. 1997; 33(11):1752-1758. [PubMed: 9470828] 
21. Gondi V, Pugh SL, Tome WA, et al. Preservation of memory with conformal avoidance of the hippocampal neural stem-cell compartment during whole-brain radiotherapy for brain metastases (RTOG 0933): a phase II multi-institutional trial. J Clin Oncol. 2014; 32(34):3810-3816. DOI: 10.1200/JCO.2014.57.2909 [PubMed: 25349290]

22. Brown PD, Pugh S, Laack NN, et al. Memantine for the prevention of cognitive dysfunction in patients receiving whole-brain radiotherapy: a randomized, double-blind, placebo-controlled trial. Neuro Oncol. 2013; 15(10):1429-1437. DOI: 10.1093/neuonc/not114 [PubMed: 23956241]

23. Xanthopoulos EP, Corradetti MN, Mitra N, et al. Impact of PET staging in limited-stage small-cell lung cancer. J Thorac Oncol. 2013; 8(7):899-905. DOI: 10.1097/JTO.0b013e31828e8996 [PubMed: 23608814]

24. O'Keefe EB, Meltzer JP, Bethea TN. Health disparities and cancer: racial disparities in cancer mortality in the United States, 2000-2010. Front public Heal. 2015 Apr.3:51.doi: 10.3389/fpubh. 2015.00051

25. Boring CC, Squires TS, Health CW. Cancer statistics for african americans. CA Cancer J Clin. 1992; 42(1):7-17. DOI: 10.3322/canjclin.42.1.7 [PubMed: 1728341]

26. Zheng L, Enewold L, Zahm SH, et al. Lung cancer survival among black and white patients in an equal access health system. Cancer Epidemiol Biomarkers Prev. 2012; 21(10):1841-1847. DOI: 10.1158/1055-9965.EPI-12-0560 [PubMed: 22899731]

27. Slotman BJ, Van Tinteren H, Praag JO, et al. Use of thoracic radiotherapy for extensive stage small-cell lung cancer: A phase 3 randomised controlled trial. Lancet. 2015; 385(9962):36-42. DOI: 10.1016/S0140-6736(14)61085-0 [PubMed: 25230595] 


\section{CLINICAL PRACTICE POINTS}

Patients diagnosed with small cell lung cancer (SCLC) have a high propensity to develop brain metastases. As such, those who respond to initial chemotherapy without developing brain metastases are often treated with prophylactic cranial irradiation (PCI) to target any microscopic intracranial disease. PCI is well established in the care of patients with limited stage disease; however, its role in the treatment of patients with extensive stage (ES) disease is more controversial, with conflicting evidence from prospective randomized trials.

The aim of this study was to determine the impact of PCI on overall survival in patients with metastatic SCLC who were treated with initial chemotherapy. In order to address this question, we utilized the National Cancer Database. After a propensity matched score analysis there was a significant survival benefit for patients who received prophylactic cranial irradiation, with a median survival of 13.9 vs. 11.1 months ( $\mathrm{p}<0.0001$ ), 1-year overall survival $61.2 \%$ vs. $44.0 \%$ ( $<<0.0001)$ and 2 -year overall survival $19.8 \%$ vs. $11.5 \%,(\mathrm{p}<0.0001)$.

Overall, this retrospective study, which is the largest in this population to date, shows that patients with metastatic SCLC treated with prophylactic cranial irradiation have significantly improved survival outcomes. In light of conflicting results from randomized trials on the role of PCI in ES-SCLC, this study adds clinically important information to help guide physician and patient decision-making about the utility of PCI in metastatic small cell lung cancer. 


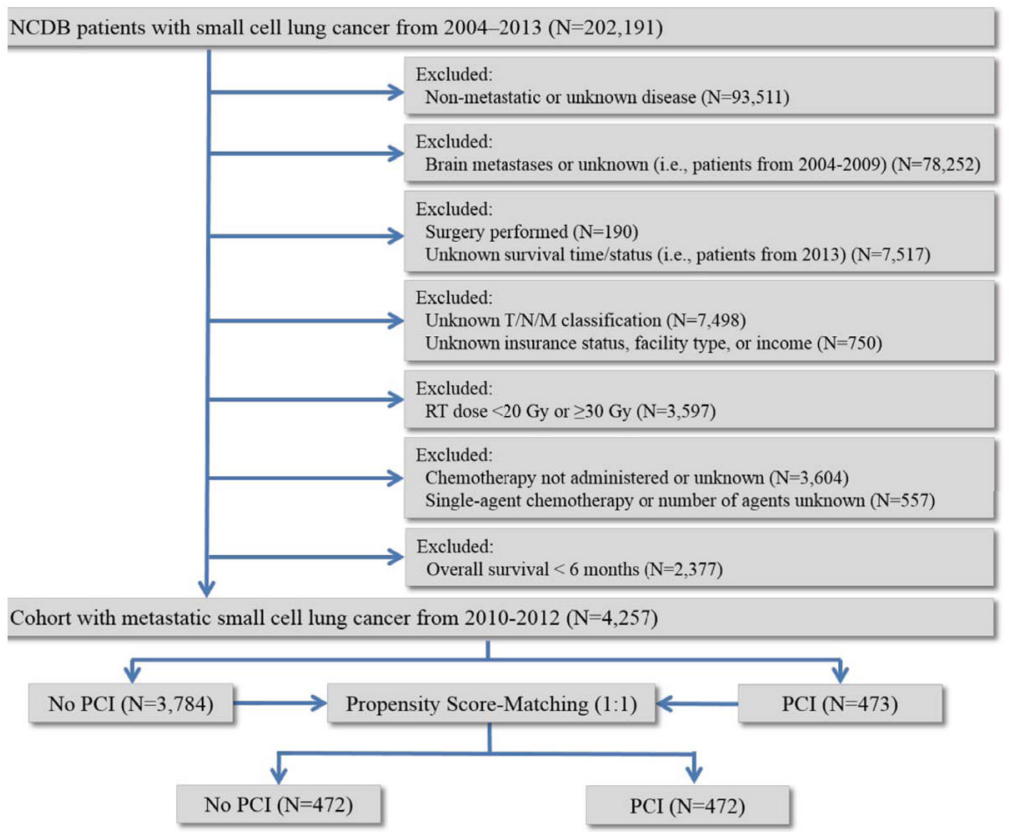

Figure 1.

Definition of patient cohort 
A.

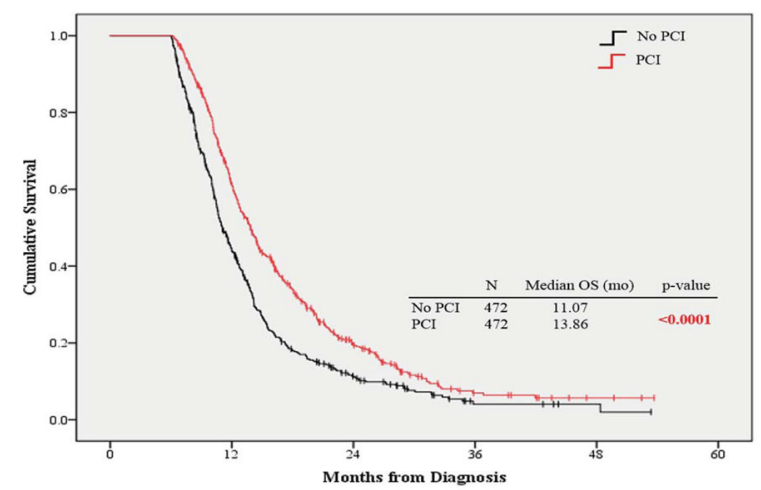

No. at risk No. at risk
NoPCI
PCI

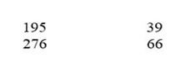

5
12
B.

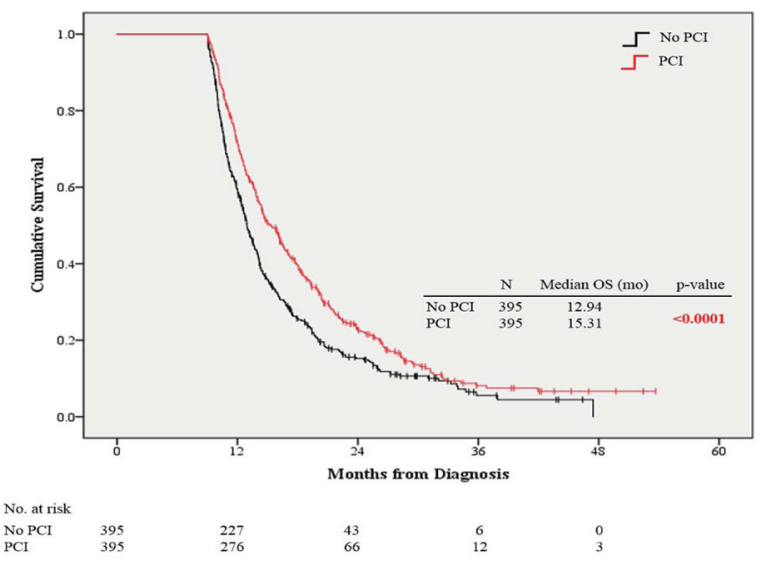

Figure 2.

Overall survival in 1:1 propensity score matched cohort with minimum OS of (A) 6 months and (B) 9 months 


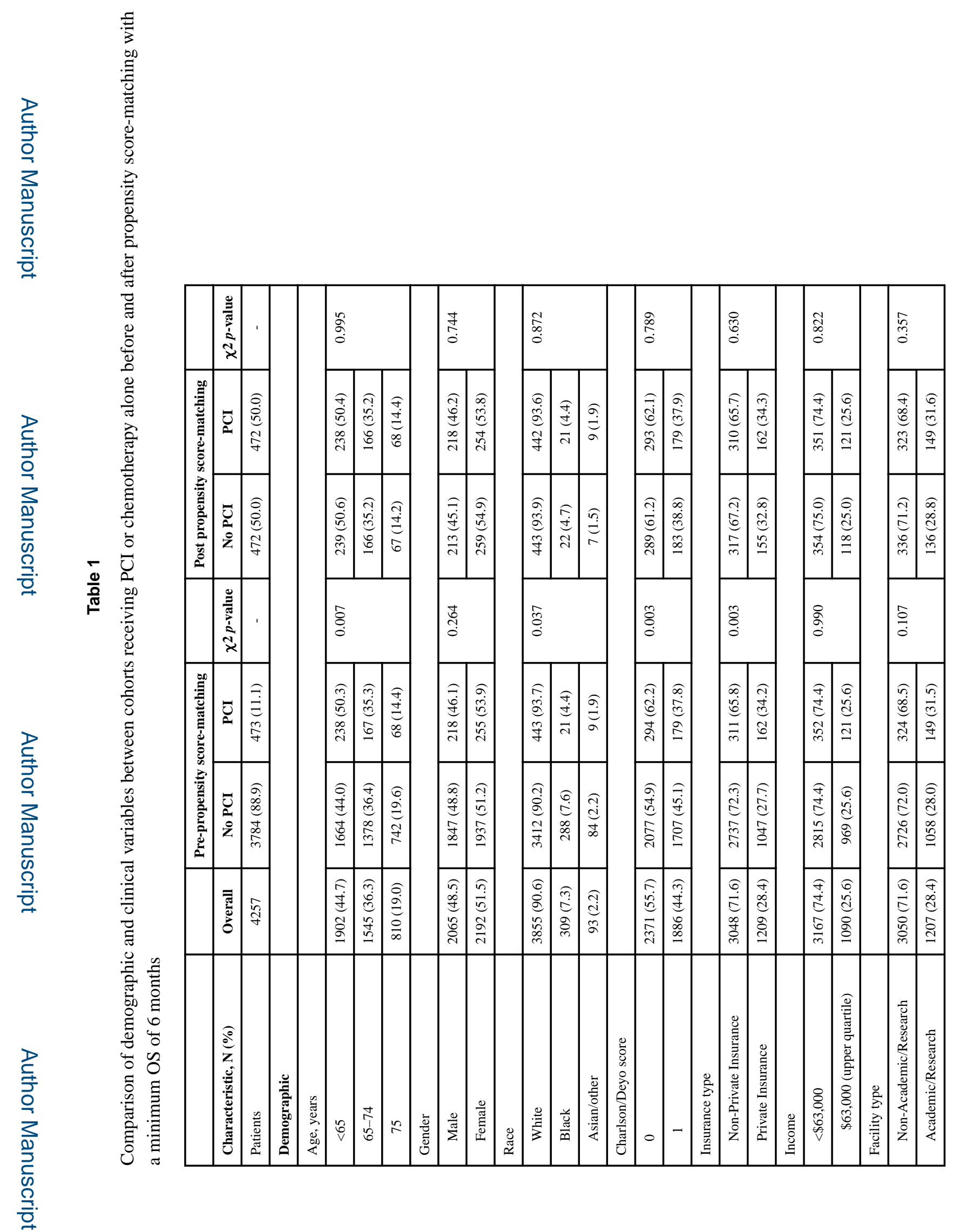

Clin Lung Cancer. Author manuscript; available in PMC 2019 May 01. 


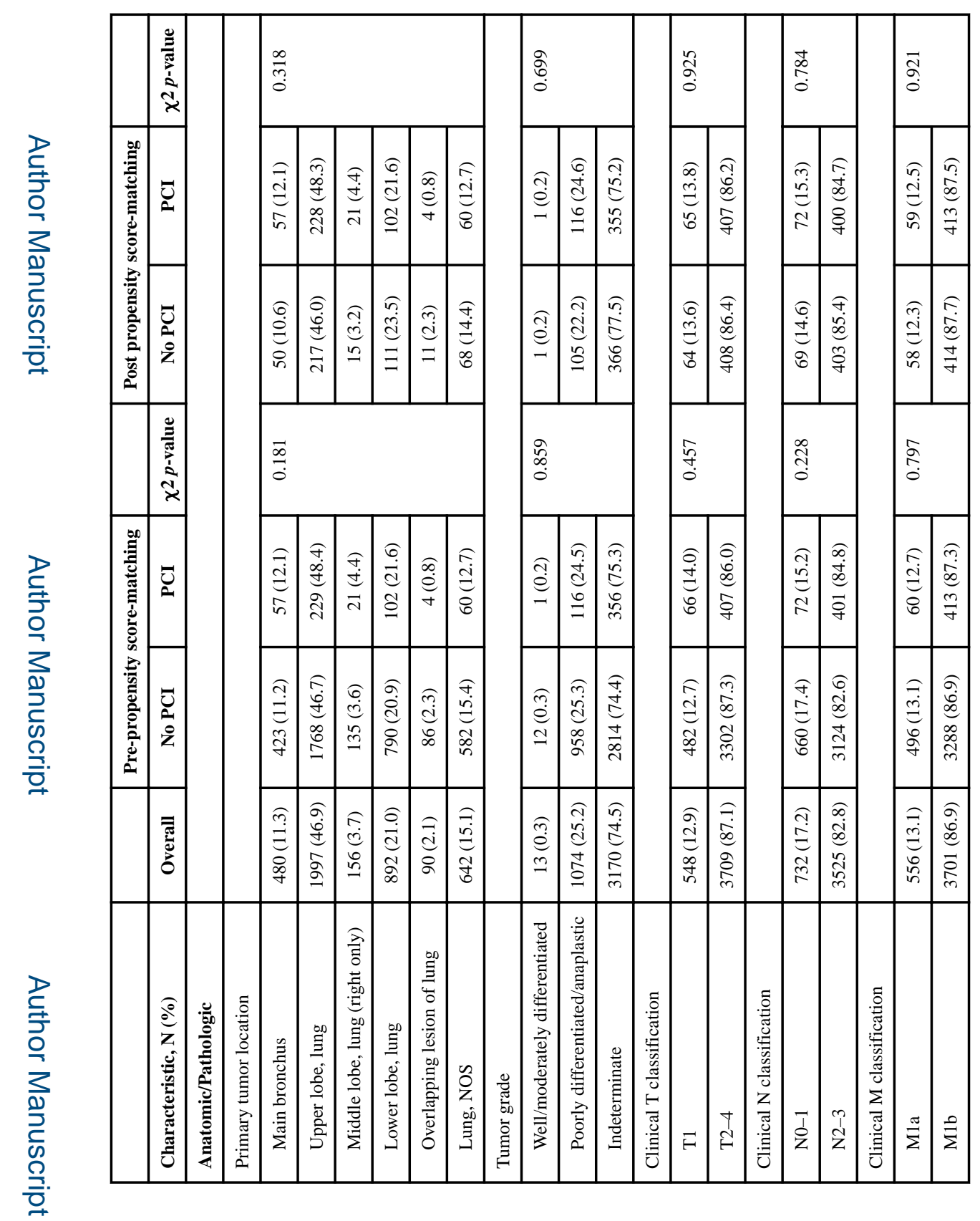

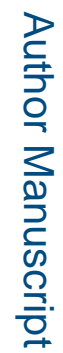


Table 2

Predictors of PCI in patients with a minimum OS of 6 months

\begin{tabular}{|c|c|c|c|c|}
\hline \multirow[b]{2}{*}{ Characteristic, $\mathbf{N}(\%)$} & \multicolumn{2}{|l|}{ Univariable } & \multicolumn{2}{|l|}{ Multivariable } \\
\hline & Odds Ratio (95\% C.I.) & $p$-value & Odds Ratio (95\% C.I.) & $p$-value \\
\hline \multicolumn{5}{|l|}{ Demographic } \\
\hline \multicolumn{5}{|l|}{ Age, years } \\
\hline$<65$ & Ref. & - & Ref. & - \\
\hline $65-74$ & $0.85(0.69-1.05)$ & 0.123 & $0.87(0.70-1.07)$ & 0.194 \\
\hline$\geq 75$ & $0.64(0.48-0.85)$ & 0.002 & $0.65(0.49-0.86)$ & 0.003 \\
\hline \multicolumn{5}{|l|}{ Gender } \\
\hline Male & Ref. & \multirow[b]{2}{*}{0.264} & - & \multirow[b]{2}{*}{-} \\
\hline Female & $1.12(0.92-1.35)$ & & - & \\
\hline \multicolumn{5}{|l|}{ Race } \\
\hline White & Ref. & - & Ref. & - \\
\hline Black & $0.56(0.36-0.88)$ & 0.013 & $0.55(0.35-0.87)$ & 0.010 \\
\hline Asian/other & $0.83(0.41-1.65)$ & 0.588 & $0.76(0.38-1.53)$ & 0.445 \\
\hline \multicolumn{5}{|l|}{ Charlson/Deyo score } \\
\hline 0 & Ref. & \multirow[b]{2}{*}{0.003} & Ref. & \multirow[b]{2}{*}{0.006} \\
\hline$\geq 1$ & $0.74(0.61-0.90)$ & & $0.76(0.62-0.93)$ & \\
\hline \multicolumn{5}{|l|}{ Insurance type } \\
\hline Non-Private Insurance & Ref. & \multirow[b]{2}{*}{0.003} & Ref. & \multirow[b]{2}{*}{-} \\
\hline Private Insurance & $1.36(1.11-1.67)$ & & - & \\
\hline \multicolumn{5}{|l|}{ Income } \\
\hline$<\$ 63,000$ & Ref. & \multirow[b]{2}{*}{0.990} & - & \multirow[b]{2}{*}{-} \\
\hline$\geq \$ 63,000$ (upper quartile) & $0.99(0.80-1.24)$ & & - & \\
\hline \multicolumn{5}{|l|}{ Facility type } \\
\hline Non-Academic/Research & Ref. & \multirow[b]{2}{*}{0.107} & Ref. & \multirow[b]{2}{*}{ - } \\
\hline Academic/Research & $1.19(0.96-1.46)$ & & - & \\
\hline \multicolumn{5}{|l|}{ Anatomic/Pathologic } \\
\hline \multicolumn{5}{|l|}{ Primary tumor location } \\
\hline Main bronchus & Ref. & - & - & - \\
\hline Upper lobe, lung & $0.96(0.71-1.31)$ & 0.802 & - & - \\
\hline Middle lobe, lung (right lung only) & $1.15(0.68-1.97)$ & 0.600 & - & - \\
\hline Lower lobe, lung & $0.96(0.68-1.35)$ & 0.808 & - & - \\
\hline Overlapping lesion of lung & $0.35(0.12-0.98)$ & 0.045 & - & - \\
\hline Lung, NOS & $0.77(0.52-1.12)$ & 0.171 & - & - \\
\hline \multicolumn{5}{|l|}{ Tumor grade } \\
\hline Well/moderately differentiated & Ref. & - & - & - \\
\hline Poorly differentiated/anaplastic & $1.45(0.19-11.28)$ & 0.721 & - & - \\
\hline Indeterminate & $1.52(0.20-11.71)$ & 0.689 & - & - \\
\hline
\end{tabular}




\begin{tabular}{|c|c|c|c|c|}
\hline \multirow[b]{2}{*}{ Characteristic, $\mathbf{N}(\%)$} & \multicolumn{2}{|l|}{ Univariable } & \multicolumn{2}{|l|}{ Multivariable } \\
\hline & Odds Ratio (95\% C.I.) & $p$-value & Odds Ratio (95\% C.I.) & $p$-value \\
\hline \multicolumn{5}{|l|}{ Clinical $\mathrm{T}$ classification } \\
\hline $\mathrm{T} 1$ & Ref. & \multirow[b]{2}{*}{0.457} & - & \multirow[b]{2}{*}{-} \\
\hline $\mathrm{T} 2-4$ & $0.90(0.68-1.19)$ & & - & \\
\hline \multicolumn{5}{|l|}{ Clinical $\mathrm{N}$ classification } \\
\hline N0-1 & Ref. & \multirow[b]{2}{*}{0.228} & - & \multirow[b]{2}{*}{-} \\
\hline $\mathrm{N} 2-3$ & $1.18(0.90-1.53)$ & & - & \\
\hline \multicolumn{5}{|l|}{ Clinical M classification } \\
\hline M1a & Ref. & \multirow[b]{2}{*}{0.797} & - & \multirow[b]{2}{*}{-} \\
\hline M1b & $1.04(0.78-1.38)$ & & - & \\
\hline
\end{tabular}


Table 3

Cox proportional hazards model for OS in unmatched patients receiving PCI or chemotherapy alone with a minimum OS of 6 months

\begin{tabular}{|c|c|c|c|c|}
\hline \multirow[b]{2}{*}{ Characteristic, N (\%) } & \multicolumn{2}{|l|}{ Univariable } & \multicolumn{2}{|l|}{ Multivariable } \\
\hline & Hazard Ratio (95\% C.I.) & $p$-value & Hazard Ratio (95\% C.I.) & $p$-value \\
\hline \multicolumn{5}{|l|}{ Demographic } \\
\hline \multicolumn{5}{|l|}{ Age, years } \\
\hline$<65$ & Ref. & - & Ref. & - \\
\hline $65-74$ & $1.14(1.06-1.22)$ & 0.001 & $1.12(1.04-1.21)$ & 0.002 \\
\hline$\geq 75$ & $1.24(1.14-1.36)$ & $<0.0001$ & $1.23(1.13-1.35)$ & $<0.0001$ \\
\hline \multicolumn{5}{|l|}{ Gender } \\
\hline Male & Ref. & \multirow[b]{2}{*}{$<0.0001$} & Ref. & \multirow[b]{2}{*}{$<0.0001$} \\
\hline Female & $0.84(0.78-0.89)$ & & $0.85(0.79-0.90)$ & \\
\hline \multicolumn{5}{|l|}{ Race } \\
\hline White & Ref. & - & Ref. & - \\
\hline Black & $0.85(0.75-0.97)$ & 0.013 & $0.83(0.73-0.94)$ & 0.004 \\
\hline Asian/other & $1.03(0.82-1.29)$ & 0.810 & $1.04(0.83-1.30)$ & 0.759 \\
\hline \multicolumn{5}{|l|}{ Charlson/Deyo score } \\
\hline 0 & Ref. & \multirow[b]{2}{*}{$<0.0001$} & Ref. & \multirow[b]{2}{*}{0.002} \\
\hline$\geq 1$ & $1.13(1.06-1.21)$ & & $1.11(1.04-1.19)$ & \\
\hline \multicolumn{5}{|l|}{ Insurance type } \\
\hline Non-Private Insurance & Ref. & \multirow[b]{2}{*}{0.004} & Ref. & \multirow[b]{2}{*}{-} \\
\hline Private Insurance & $0.90(0.84-0.97)$ & & - & \\
\hline \multicolumn{5}{|l|}{ Income } \\
\hline$<\$ 63,000$ & Ref. & \multirow[b]{2}{*}{0.031} & Ref. & \multirow[b]{2}{*}{0.007} \\
\hline$\geq \$ 63,000$ (upper quartile) & $0.92(0.86-0.99)$ & & $0.90(0.84-0.97)$ & \\
\hline \multicolumn{5}{|l|}{ Facility type } \\
\hline Non-Academic/Research & Ref. & \multirow[b]{2}{*}{0.025} & Ref. & \multirow[b]{2}{*}{0.088} \\
\hline Academic/Research & $0.92(0.86-0.99)$ & & $0.94(0.87-1.01)$ & \\
\hline \multicolumn{5}{|l|}{ Anatomic/Pathologic } \\
\hline \multicolumn{5}{|l|}{ Primary tumor location } \\
\hline Main bronchus & Ref. & - & - & - \\
\hline Upper lobe, lung & $0.87(0.78-0.97)$ & 0.009 & - & - \\
\hline Middle lobe, lung (right lung only) & $0.98(0.81-1.19)$ & 0.826 & - & - \\
\hline Lower lobe, lung & $0.91(0.81-1.03)$ & 0.121 & - & - \\
\hline Overlapping lesion of lung & $0.94(0.73-1.19)$ & 0.583 & - & - \\
\hline Lung, NOS & $0.95(0.84-1.08)$ & 0.430 & - & - \\
\hline \multicolumn{5}{|l|}{ Tumor grade } \\
\hline Well/moderately differentiated & Ref. & - & - & - \\
\hline Poorly differentiated/anaplastic & $1.84(0.95-3.55)$ & 0.069 & - & - \\
\hline
\end{tabular}

Clin Lung Cancer. Author manuscript; available in PMC 2019 May 01. 


\begin{tabular}{|c|c|c|c|c|}
\hline & \multicolumn{2}{|l|}{ Univariable } & \multicolumn{2}{|l|}{ Multivariable } \\
\hline Characteristic, $\mathbf{N}(\%)$ & Hazard Ratio (95\% C.I.) & $p$-value & Hazard Ratio (95\% C.I.) & $p$-value \\
\hline Indeterminate & $1.74(0.91-3.35)$ & 0.097 & - & - \\
\hline \multicolumn{5}{|l|}{ Clinical T classification } \\
\hline $\mathrm{T} 1$ & Ref. & \multirow[b]{2}{*}{0.013} & Ref. & \multirow[b]{2}{*}{0.004} \\
\hline $\mathrm{T} 2-4$ & $1.13(1.03-1.25)$ & & $1.16(1.05-1.27)$ & \\
\hline \multicolumn{5}{|l|}{ Clinical $\mathrm{N}$ classification } \\
\hline N0-1 & Ref. & \multirow[b]{2}{*}{0.001} & Ref. & \multirow[b]{2}{*}{0.001} \\
\hline $\mathrm{N} 2-3$ & $1.15(1.06-1.25)$ & & $1.15(1.06-1.26)$ & \\
\hline \multicolumn{5}{|l|}{ Clinical M classification } \\
\hline M1a & Ref. & \multirow[b]{2}{*}{0.000} & Ref. & \multirow[b]{2}{*}{$<0.0001$} \\
\hline M1b & $1.19(1.08-1.31)$ & & $1.22(1.11-1.35)$ & \\
\hline \multicolumn{5}{|c|}{ Prophylactic cranial irradiation } \\
\hline No & Ref. & \multirow[b]{2}{*}{$<0.0001$} & Ref. & \multirow[b]{2}{*}{$<0.0001$} \\
\hline Yes & $0.66(0.59-0.73)$ & & $0.66(0.60-0.74)$ & \\
\hline
\end{tabular}

Abbreviations: NOS, not otherwise specified 
Table 4A

Follow-up and OS information for the propensity matched cohort with a minimum OS of 6 months

\begin{tabular}{|l|c|c|c|c|}
\hline & & \multicolumn{2}{|c|}{ PCI } & \\
\hline Variable, months (IQR) or \% & Overall & No (n=472) & Yes (n=472) & p-value \\
\hline Follow-up, median (IQR) & $30.39(23.26-42.28)$ & $29.31(23.26-42.71)$ & $30.39(23.29-42.28)$ & - \\
\hline Median OS, median (IQR) & $12.45(9.40-18.43)$ & $11.07(8.48-15.38)$ & $13.86(10.22-21.13)$ & \multirow{2}{*}{$<0.0001^{*}$} \\
\hline 1-year actuarial survival & 52.8 & 44.0 & 61.2 & \multirow{2}{*}{$<0.0001^{* * *}$} \\
\hline 2-year actuarial survival & 15.6 & 11.5 & 19.8 & \\
\cline { 1 - 3 }
\end{tabular}

* $\log$ rank test,

W** Wilcoxon (Gehan) statistic

Interquartile Range (IQR) 


\section{Table 4B}

Follow-up and OS information for the propensity matched cohort with a minimum OS of 9 months

\begin{tabular}{|l|c|c|c|c|}
\hline & & \multicolumn{2}{|c|}{ PCI } & \\
\cline { 1 - 4 } Variable, months (IQR) or \% & Overall & No (n=395) & Yes (n=395) & p-value \\
\hline Follow-up, median (IQR) & $29.90(23.29-42.09)$ & $29.83(22.51-37.82)$ & $30.72(23.82-42.28)$ & - \\
\hline Median OS, median (IQR) & $14.00(10.87-20.47)$ & $12.94(10.51-18.69)$ & $15.31(11.70-22.47)$ & \multirow{2}{*}{$<0.0001^{*}$} \\
\cline { 1 - 4 } 1-year actuarial survival & 65.5 & 59.5 & 71.4 & \multirow{2}{*}{$* 0.0001^{* *}$} \\
\hline
\end{tabular}

* $\log$ rank test

*** Wilcoxon (Gehan) statistic

Interquartile Range (IQR) 